\title{
Will it hurt, doctor? Factors predicting patients' experience of pain during double contrast examination of the colon
}

\section{Siri Steine}

Department of General Practice, University of Oslo, 0264 Oslo 2, Norway Siri Steine, research fellow

BMF 1993;307:100
Knowledge of patients' reactions is important when choosing among different examination procedures, and when informing patients beforehand. This study describes patients' pain during double contrast barium enema and identifies predictors for it in a consecutive series of patients referred from primary health care.

\section{Patients, methods, and results}

A total of 2270 patients (mean age 55 years; $64 \%$ female) were examined by double contrast barium enema at an outpatient clinic in Oslo.

The colon preparation comprised two days with a liquid diet and a laxative (Pico-salax). The radiological procedure was based on the methods described by Fork. $^{1}$ Examination length, medication, patient cooperation, technical quality of the radiographs, and pathological results were recorded. The patients recorded their discomfort during the colon preparation and discomfort or pain during the examination on a progressive 10 point scale from 1 (no pain or discomfort) to 10 (extreme pain or discomfort) before leaving the clinic. Only the results related to discomfort during colon preparation and pain during the barium examination are reported here.

The study was approved by the regional ethics committee.

The $\chi^{2}$ test, two tailed $t$ test, and Pearson's correla-

Factors related to pain during double contrast barium enema as derived from multivariate logistic analysis

\begin{tabular}{|c|c|c|c|}
\hline & \multicolumn{3}{|c|}{$\begin{array}{l}\text { Severe pain }(\mathrm{n}=252) v \text { no or moderate pain } \\
\qquad(\mathrm{n}=2018)^{\star}\end{array}$} \\
\hline & $\begin{array}{l}\text { No of } \\
\text { patients }\end{array}$ & $\begin{array}{l}\text { Odds ratio } \\
\text { ( } 95 \% \text { confidence interval) }\end{array}$ & $\mathrm{p}$ Value \\
\hline \multicolumn{4}{|l|}{ Age: } \\
\hline $14-24$ & 142 & $1 \cdot 0$ & 0.07 \\
\hline $25-29$ & 118 & $0.6(0 \cdot 3$ to $1 \cdot 1)$ & 0.07 \\
\hline $30-34$ & 119 & $0.5(0.3$ to 1.0$)$ & 0.05 \\
\hline $35-39$ & 117 & $0.5(0.2$ to 0.9$)$ & 0.03 \\
\hline $40-44$ & 160 & $0.4(0.2$ to 0.7$)$ & 0.002 \\
\hline $45-49$ & 159 & $0.4(0.2$ to 0.8$)$ & 0.01 \\
\hline $50-54$ & 174 & $0.3(0.1$ to 0.6$)$ & $<0.001$ \\
\hline $55-59$ & 181 & $0.3(0.1$ to 0.6$)$ & $<0.001$ \\
\hline $60-64$ & 267 & $0.2(0.1$ to 0.4$)$ & $<0.001$ \\
\hline $65-69$ & 283 & $0.2(0.1$ to 0.5$)$ & $<0.001$ \\
\hline $70-74$ & 256 & $0.2(0.1$ to 0.5$)$ & $<0.001$ \\
\hline 75-79 & 185 & $0.4(0.2$ to 0.8$)$ & 0.006 \\
\hline$\geqslant 80$ & 89 & $0.7(0.3$ to 1.4$)$ & $0 \cdot 3$ \\
\hline \multicolumn{4}{|l|}{ Sex: } \\
\hline Male & 820 & $1 \cdot 0$ & \\
\hline Female & 1430 & $0.7(0.6$ to 1.0$)$ & 0.06 \\
\hline \multicolumn{4}{|c|}{ Discomfort during bowel preparation: } \\
\hline None or little & 696 & $1 \cdot 0$ & \\
\hline Moderate & 1240 & $1 \cdot 8(1 \cdot 2$ to $2 \cdot 7)$ & 0.05 \\
\hline Severe & 314 & $10 \cdot 0(6.5$ to 15.3$)$ & $<0.001$ \\
\hline \multicolumn{4}{|c|}{ Patients' capability for cooperation: } \\
\hline Good & 1863 & $1 \cdot 0$ & \\
\hline Satisfactory & 333 & $1.5(1.0$ to $2 \cdot 3)$ & 0.05 \\
\hline Poor & 54 & $2 \cdot 3(1.1$ to 4.8$)$ & 0.03 \\
\hline \multicolumn{4}{|c|}{ Radiological result: } \\
\hline Normal & 1227 & $1 \cdot 0$ & \\
\hline Pathological & 1023 & $0.9(0.6$ to 1.3$)$ & 0.5 \\
\hline
\end{tabular}

* The pain variable was divided into the categories no or moderate pain (score 1-6) and severe pain (score 7-10). Analyses with different cutpoints (between 5 and 6 , and between 7 and 8 ) implied insignificant changes regarding the main results. Pain scored 1 was experienced by 266 patients, 2 by 314,3 by 280,4 by 425,5 by 562,6 by 211,7 by 121,8 by 59,9 by 25 , and 10 by 47.20 patients were excluded from this analysis because of missing tion test were used in bivariate analyses. A p value $\leqslant 0.05$ was regarded as significant. Multivariate logistic regression models included variables significantly associated with patients' pain together with patients' age and sex. ${ }^{2}$

The mean (SD) score was $4 \cdot 2(2 \cdot 0): 226$ patients (10\%) experienced no pain; $252(11 \%)$ reported severe pain. Significantly more patients $\leqslant 34$ and $\geqslant 80$ years of age experienced severe pain than patients between 35 and 79 years of age (table). Other predictors for severe pain were discomfort during colon preparation and reduced cooperation (that is, physical disability and communication difficulties).

Radiographs were of suboptimal technical quality in 662 patients, mainly because of inadequate colon preparation. Patients with incomplete colon preparation reported significantly more discomfort in connection with the preparation than patients with a "clean colon" ( $p=0.02, t$ test $)$.

Examination time or medication given intravenously before air filling (butylscopolamine bromide or glucagon) were not associated with the degree of pain. No specific diagnosis-for example, polyps, tumour, or diverticular or inflammatory bowel diseasescontributed to the degree of pain in the multivariate analysis. Nor were symptoms, including rectal and abdominal pain, or previous colorectal disorders, including irritable bowel syndrome and inflammatory diseases, predictors of severe pain during the examination.

\section{Comment}

Double contrast barium enemas can give extreme pain, and our finding that the youngest patients suffered most is important in the context of general practitioners' referral decisions; they should favour a restrictive referral practice under the age of $40 .{ }^{3}$ The relatively high occurrence of pain in the oldest age group should lead to better information and care instead of fewer referrals, since serious bowel disease is more common at this age. ${ }^{4}$

The irritable bowel syndrome, present in $20 \%$ of the patients (454/2270) but only in $11 \%$ under the age of 40 (55/496) may have caused increased pain due to disturbed intestinal motility or psychological distress. ${ }^{5}$ As this condition is often diagnosed only after extensive investigations with normal results it may, especially in young patients, have been unrecognised at the time of the examination.

The significant association between incomplete colon preparation and a high degree of discomfort during the preparation emphasises the importance of informing patients of the need for a "clean colon." Discomfort during colon preparation was also a highly significant predictor of severe pain during the examination. Thus, consideration of the patient's age, together with a simple question about how she or he felt during the colon preparation, may increase the examiner's awareness, empathy, and care during the invading and potentially debasing double contrast examination.

1 Fork FT. The diagnostic value of large bowel radiography in contemporary medicine. Malmø: Department of Diagnostic Radiology, University of Lund, Malmø General Hospital, 1982.

2 Hosmer DW, Lemenshow S. Applied logistic regression. New York: Wiley, 1989.

3 Steine S, Loken K. Lxrum E. Age and sex: underestimated selection criteria for referral to X-ray examination of the colon? Scand 8 Prim Health Care $1992 ; 10: 134-8$.

Incidence of cancer in Norway 1982-1986. Oslo: Cancer Registry of Norway, 1990.

5 Moriarty KJ. The irritable bowel syndrome. BMF 1992;304:1166-9. 